\title{
The Spatial Distribution of Precipitation in Northwest China
}

\author{
Chuancheng Zhao, ${ }^{1,2}$ Shuxia Yao, ${ }^{2}$ Jun Liu, $^{2}$ and Jian Wang ${ }^{1}$ \\ ${ }^{1}$ State Key Laboratory of Cryospheric Sciences, Cold and Arid Regions Environmental and Engineering Research Institute, \\ Chinese Academy of Sciences, Lanzhou 730000, China \\ ${ }^{2}$ Lanzhou City University, Lanzhou 730070, China
}

Correspondence should be addressed to Shuxia Yao; yaoshuxia@153.com

Received 9 July 2014; Revised 12 August 2014; Accepted 13 August 2014; Published 1 September 2014

Academic Editor: Zhihua Zhang

Copyright (C) 2014 Chuancheng Zhao et al. This is an open access article distributed under the Creative Commons Attribution License, which permits unrestricted use, distribution, and reproduction in any medium, provided the original work is properly cited.

\begin{abstract}
Northwestern China has an extremely complex climate due to the varied terrain and complexities of climate change where the environment is sensitive to both regional and global climate change. We employed the Mann-Kendal test to investigate trends of precipitation distributions using annual, seasonal, and monthly data records from 1960 to 2008. On the whole, the variations in precipitation patterns are more complex than those for temperature. The trends of annual, seasonal, and monthly precipitation have shown remarkable differences between the east and west. In the west such as in northern Xinjiang and western Qinghai, the variation is a significant increase, consistent with the temperature change, whereas in the east such as in eastern Gansu, and southern Shaanxi, the variation is a remarkable decrease, opposite to the change observed in temperatures.
\end{abstract}

\section{Introduction}

The climate warming trend has been well documented at many locations around the world during the last several decades. This trend is projected to accelerate in the future and has great implications for hydrological cycle and water resources planning [1]. The climate warming has been linked to serious ecological and environmental deterioration and extreme climate events, such as flooding, drought, and other disasters, resulting in increasing social and economic losses [2]. It is well known that precipitation displays the most important predictor in hydrological studies [3]. Therefore, understanding the spatial and temporal variability of precipitation is important not only to weather forecasters and climate scientists, but also to a wide range of related decisionmakers, including hydrologists, agriculturalists, emergency managers, and industrialists $[4,5]$. Precipitation has large random spatial variability and is caused by the influence of the large-scale atmospheric circulation which can be modified by local-scale parameters such as orography, wind exposure, precipitation shadow, and direction of mountain range [6]. Many articles analysed the spatial variability of precipitation using different methods, for example, MannKendall test, Wavelet, entropy using ground-based observations, or radar and satellite measurements [7-10].

Precipitation is one of the most important indicators of the availability of water resources in a region. Changes to precipitation due to, for example, climate change, may vary greatly from region to region [11, 12]. Northwestern China is climatically complex. It is affected by the Indian and East Asian summer monsoons from the southwest and southeast, respectively, by westerly airflow in both summer and winter and by northerly circulation in winter [13]. In recent years, several studies of this region have been published which detected climate change on a national and global scale. Over the most recent 50 years, the annual mean surface air temperature has increased by $1.1^{\circ} \mathrm{C}$ in China, that is, a warming rate of $0.22^{\circ} \mathrm{C}$ per hundred years, significantly higher than the Northern Hemisphere's and global average rates of warming in the same period [14]. From the mid-1980s, the temperature in the northwest region began to rise rapidly, by more than $0.63^{\circ} \mathrm{C}[15]$, slightly higher than the national 
average level. Precipitation in the western region is predicted to increase in summer but will decrease in the eastern part of Northwest China with doubled $\mathrm{CO}_{2}[16]$.

The aim of this study is to examine long-term trends of precipitation using the Mann-Kendall trend test [17, 18], which is widely used for the assessment of the significance of trends in hydrometeorological time series. The MannKendall trend test has the advantage that its power and significance are not affected by the actual distribution of the meteorological data, for example, temperature and precipitation. The Mann-Kendall test, as well as other nonparametric trend tests, is therefore more suitable for detecting trends in hydrological time series, which are often skewed and may be contaminated with outliers [7].

\section{Materials and Methods}

2.1. Study Area. The present study focuses on northwestern China, covering the provinces of Shaanxi, Gansu, and Qinghai, the autonomous regions of Ningxia and Xinjiang, and a portion of Inner Mongolia (Figure 1). The total area of the region is 3.34 million $\mathrm{km}^{2}$, comprising approximately onethird of China's land area. Precipitation derived from the Asian summer monsoons currently extends to the southern and eastern parts of our study area, although the summer monsoon penetrated markedly further north during the early to mid-Holocene. The annual precipitation decreases from southeast $(800 \mathrm{~mm})$ to northwest $(50 \mathrm{~mm})$. Arid regions occupy a vast area of northwestern China, where the mean annual precipitation is less than $250 \mathrm{~mm}$. Within the region, annual precipitation in the western plains averages 50$150 \mathrm{~mm}$ and less than $50 \mathrm{~mm}$ in the Taklimakan Desert.

2.2. Data Collection. To investigate the general trends in climatic conditions for locations in Northwest China, monthly temperature and precipitation data records for 1960-2008 from 204 stations (Figure 1) were obtained from the China Meteorological Administration (CMA) observation archives. These datasets were the longest consistent data series available and are the basis of analyses performed to assess monthly, seasonal, and annual change. For several stations, missing data have been spatially interpolated to provide homogeneous and complete series.

2.3. Trend Detection Test. The time series of temperature and precipitation were analyzed using the Mann-Kendall nonparametric trend test. This test enables the investigation of long-term precipitation tendencies, without assuming that a given dataset follows a normal distribution.

The Mann-Kendall test was applied to annual, seasonal, and monthly precipitation data. The test statistic, $S$, is calculated as

$$
S=\sum_{i=1}^{n-1} \sum_{j=i+1}^{n} \operatorname{sign}\left(y_{j}-y_{i}\right)
$$

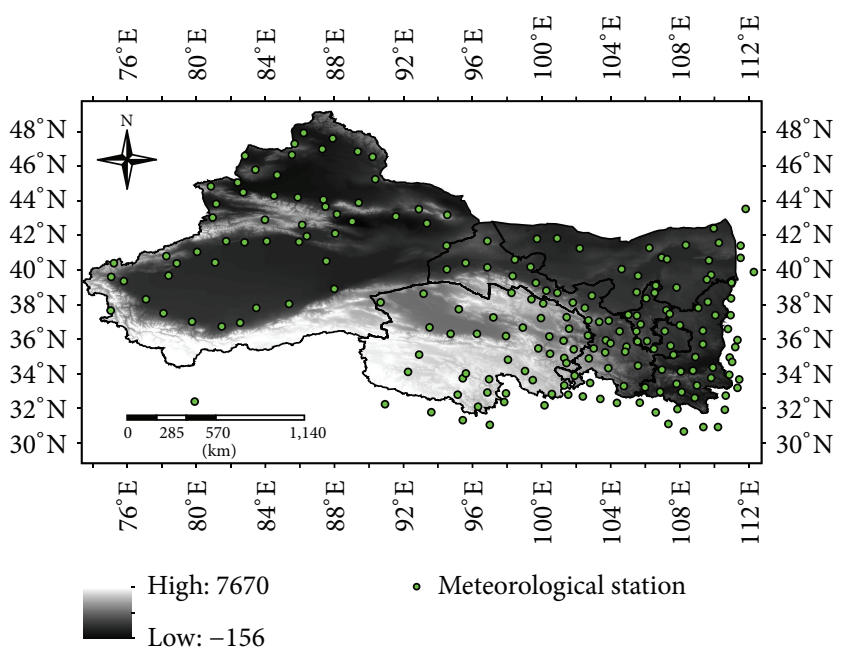

FIGURE 1: Locations of temperature and precipitation recording stations in northwestern China.

where $y_{i}$ and $y_{j}$ are the data values at times $i$ and $j, n$ is the length of the dataset, and

$$
\operatorname{sign}(y)= \begin{cases}1 & \text { if } y>0 \\ 0 & \text { if } y=0 \\ -1 & \text { if } y<0\end{cases}
$$

With the null hypothesis that $y_{i}$ are independent and randomly ordered, the statistic $S$ is approximately normally distributed when $n \geq 8$. Trends for an increase or a decrease result in $S$ being negative or positive, respectively. The expected value and variance of $S$ are given by

$$
\begin{gathered}
E[S]=0 \\
V(S)=\frac{n(n-1)(2 n+5)}{18} .
\end{gathered}
$$

The standardized test statistic, $Z$, computed by

$$
Z= \begin{cases}\frac{S-1}{\sqrt{V(S)}} & \text { if } S>0 \\ 0 & \text { if } S=0 \\ \frac{S+1}{\sqrt{V(S)}} & \text { if } S<0\end{cases}
$$

follows a standard normal distribution. Trends for an increase or a decrease result in $Z$ being negative or positive, respectively. In this study, 90\%, 95\%, and 99\% confidence levels were considered. When $|Z|$ is greater than or equal to $1.28,1.64$, and 2.32, the indicated confidence level passes $90 \%, 95 \%$, and $99 \%$, respectively.

A nonparametric robust estimate of the magnitude of the slope of linear trend, $\beta$, determined by [19], is given by

$$
\beta=\operatorname{Median}\left[\frac{\left(y_{j}-y_{i}\right)}{(j-i)}\right], \quad \forall i<j,
$$


in which $1<j<i<n$. The estimator $\beta$ is the median overall combination of record pairs for the whole dataset and is thereby resistant to the effect of extreme values in the observations. A positive value of $\beta$ indicates the time series has an upward trend. Otherwise, the time series has a downward trend.

\section{Results and Discussion}

3.1. Precipitation Trends. To support the analysis of annual, seasonal, and monthly precipitation trends, the precipitation concentration index was first calculated on a monthly basis for each station. The distribution of the precipitation concentration indices provides insight into regional heterogeneities in precipitation trends. On the whole, annual precipitation was affected much more by variations in monthly precipitation in regions including most of Xinjiang, Qinghai, western Gansu, and Inner Mongolia. In contrast, annual precipitation was affected most by variations of seasonal precipitation in locations such as Altay in Xinjiang, southeast of Gansu, and Shaanxi.

3.1.1. Annual Trend. Due to topography, elevation, and other factors, the annual mean precipitation change is not consistent with annual mean temperature changes. Figure 2 shows that the trend of annual mean precipitation has generally increased, although significant differences exist in the trend between the east and west during 1960-2008 in Northwest China. The Altai Mountains and central Tian Shan Mountains have experienced the greatest increases in annual mean precipitation, in excess of $10 \mathrm{~mm}$ per decade. In west central Xinjiang and southwest and central Qinghai, annual mean precipitation has increased above $5 \mathrm{~mm}$ per decade. The greatest decrease has occurred in Gansu (east of the Yellow River) and central Shaanxi, where the change is more than $-25 \mathrm{~mm}$ per decade. Northeast of Gansu and Shaanxi and south of Ningxia annual mean precipitation has decreased by about $-20 \mathrm{~mm}$ per decade. Thus, the variation of annual mean precipitation is evident.

3.1.2. Seasonal Trends. The distribution of seasonal precipitation is generally concentrated in spring, summer, and fall, accounting for $20 \%, 40 \%$, and $35 \%$, respectively, whereas only $5 \%$ annual precipitation arrives in the winter. Thus, variations of the seasonal precipitation in spring, summer, and fall can affect the annual precipitation in the study area significantly. Through $Z$ value analysis, variations in seasonal precipitation over time have not been found to be significant for most of Northwest China where trend analysis shows weakly varying increases and decreases. Based on the spatial analysis $\beta$ of linear slopes (Figure 3 ), the results show that precipitation in the whole study area increases in the winter, mainly concentrated in northern Xinjiang, southern Qinghai, and central Shaanxi, with the highest rates above $4 \mathrm{~mm}$ per decade. The increase in spring precipitation is widespread in Northwest China, with southern Qinghai and northern Xinjiang seeing the greatest increases above $5 \mathrm{~mm}$ per decade. On the other hand, decreases are shown in
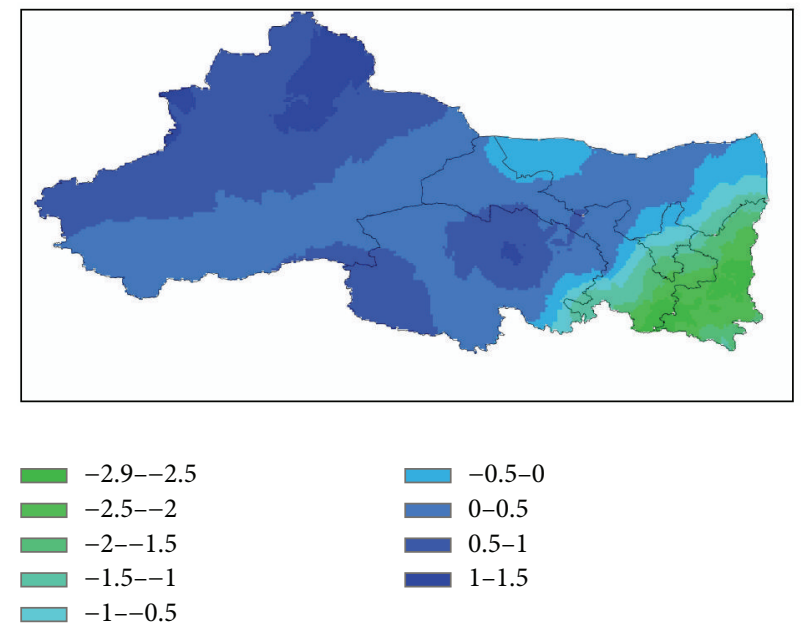

FIGURE 2: Spatial distribution of $\beta$-values for annual mean precipitation during 1960-2008. Quantities show changes in annual precipitation in $\mathrm{mm}$ per decade.

Shaanxi, Ningxia, eastern Gansu, and central Inner Mongolia, with the downtrend in southern Shaanxi having the greatest decrease at rates below $-17 \mathrm{~mm}$ per decade. The increase of summer precipitation, as shown for the spring, is widespread. However, the region of decreasing precipitation is greater for summer than for spring, and the same can be said for precipitation volumes as well. The significant increase in fall precipitation is mainly concentrated in the Tian Shan Mountains and southern Qinghai, while decreasing most significantly in the northeastern Gansu and southern Shaanxi.

3.1.3. Monthly Trends. Variations in monthly precipitation have obvious direct impact on seasonal and annual precipitation. So, the same spatial analysis was carried out using monthly precipitation figures. The result shows the two most remarkable months, which have the most significant variation. The precipitation trend in most regions has increased in July, generally in excess of $5 \mathrm{~mm}$ per decade; for example, observe most of Xinjiang and north and central Qinghai. Contrasting this, precipitation trends in most regions show a decrease in September, for example, northern Xinjiang, southern Qinghai and Ningxia, eastern Gansu, and Shaanxi, where the largest decrease is below $-13 \mathrm{~mm}$ per decade, for example, in northern Shaanxi.

\section{Conclusions}

The aim of this study has been to catalog the spatial distribution of precipitation trends in Northwest China during 1960-2008. The results have shown that the spatial distribution of annual mean precipitation has clearly changed over nearly the last 50 years. Elevation has had a remarkable influence on temperature, whereas precipitation has been affected significantly by topography, hydraulic transport, and 

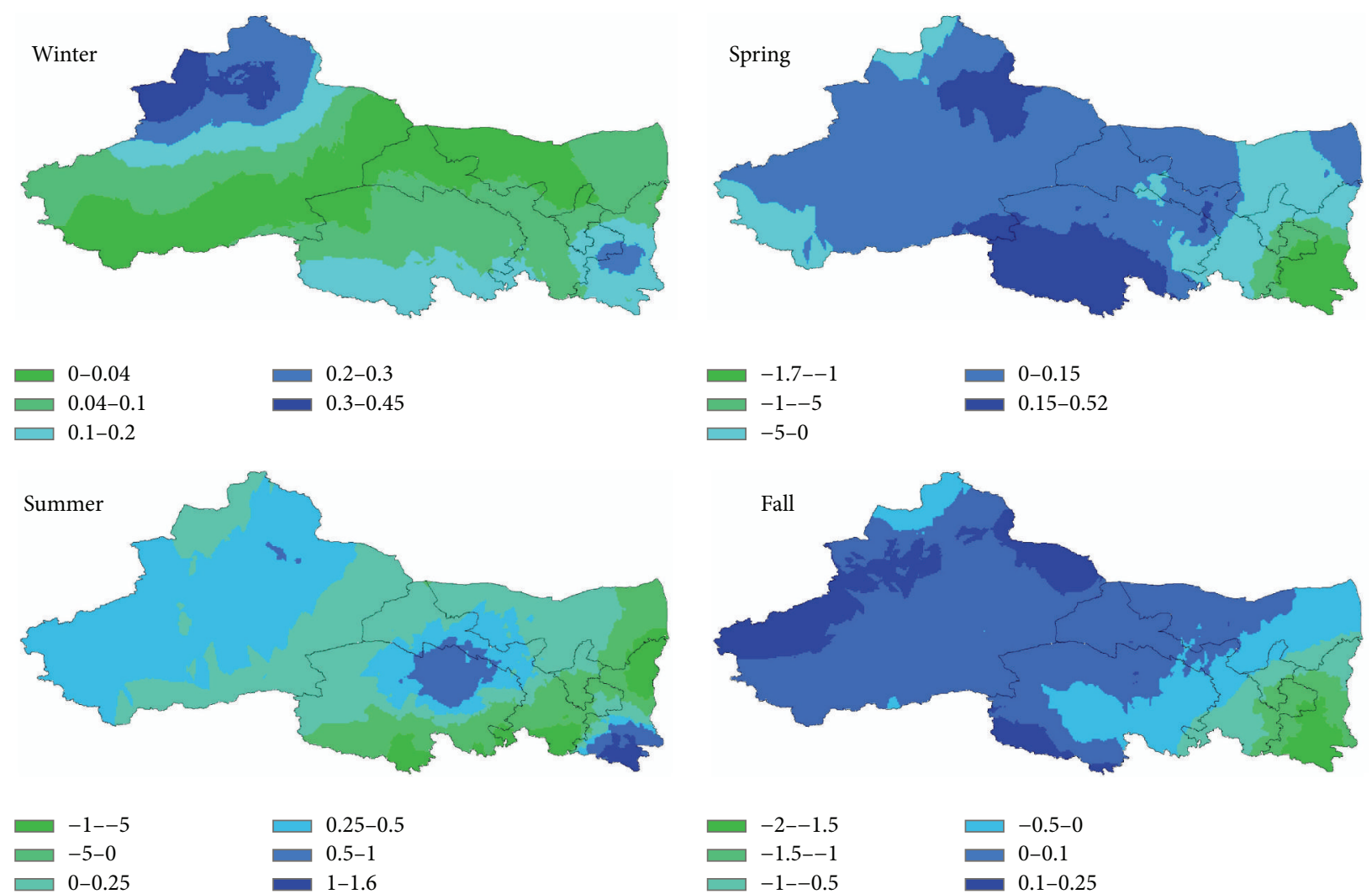

$\square-1.5--1$

Figure 3: Spatial distribution of $\beta$-values for seasonal precipitation during 1960-2008. Quantities show changes in annual precipitation in mm per decade.

geographic position. The trends of annual, seasonal, and monthly precipitation appear to be distinctly polarized by geography; in the west, the increasing trend is significant, and in the east, a remarkable decrease is found. Thus, the trends of temperature and precipitation show a weak positive correlation in parts of Northwest China such as Xinjiang and Qinghai and a negative correlation in regions such as eastern Gansu, Shaanxi, and southern Ningxia.

\section{Conflict of Interests}

The authors declare that there is no conflict of interests regarding the publication of this paper.

\section{Acknowledgments}

The authors are grateful to the two anonymous reviewers for their very useful suggestions and comments. This study was supported by Major National Science Research Program (973 Program) (no. 2013CBA01806), the National Natural Science Foundation of China (41361013 and 31300388), State Key Laboratory of Cryosphere Open Fund (SKLCS 2012-10), and Lanzhou City University Ph.D. Research Fund (LZCUBS2013-09 and LZCU-BS2013-12).

\section{References}

[1] O. I. Abdul Aziz and D. H. Burn, "Trends and variability in the hydrological regime of the Mackenzie River Basin," Journal of Hydrology, vol. 319, no. 1-4, pp. 282-294, 2006.

[2] J. M. Wang and D. Wei, "Cognition research on global climate change," China Population, Resources and Environment, vol. 18, no. 3, pp. 58-63, 2008.

[3] M. Constantin, M. Ileana, H. Heike, M. Mihaela, C. Ulrich, and S. Petre, "A hidden Markov model applied to the daily spring precipitation over the Danube basin," Advances in Meteorology, vol. 2014, Article ID 237247, 11 pages, 2014.

[4] E. E. Ebert, J. E. Janowiak, and C. Kidd, "Comparison of nearreal-time precipitation estimates from satellite observations and numerical models," Bulletin of the American Meteorological Society, vol. 88, no. 1, pp. 47-64, 2007.

[5] N. A. Brunsell, "A multiscale information theory approach to assess spatial-temporal variability of daily precipitation," Journal of Hydrology, vol. 385, no. 1-4, pp. 165-172, 2010.

[6] R. Zuzana and K. Jan, "Trends of convective and stratiform precipitation in the Czech Republic, 1982-2010," Advances in Meteorology, vol. 2014, Article ID 647938, 11 pages, 2014.

[7] K. H. Hamed, "Trend detection in hydrologic data: the MannKendall trend test under the scaling hypothesis," Journal of Hydrology, vol. 349, no. 3-4, pp. 350-363, 2008.

[8] A. K. Mishra, M. Özger, and V. P. Singh, "An entropy-based investigation into the variability of precipitation," Journal of Hydrology, vol. 370, no. 1-4, pp. 139-154, 2009. 
[9] Z. Sokol and V. Bližňák, "Areal distribution and precipitationaltitude relationship of heavy short-term precipitation in the Czech Republic in the warm part of the year," Atmospheric Research, vol. 94, no. 4, pp. 652-662, 2009.

[10] H. Y. Lam, L. Luini, J. Din, C. Capsoni, and A. D. Panagopoulos, "Stratiform and convective rain discrimination for equatorial region," in Proceedings of the 8th IEEE Student Conference on Research and Development-Engineering: Innovation and Beyond (SCOReD '10), pp. 112-116, December 2010.

[11] J. T. Houghton, Y. H. Ding, D. J. Griggs et al., "Climate change 2001: the scientific basis," in Contribution of Working Group I to the Third Assessment Report of the Intergovernmental Panel on Climate Change, Cambridge University Press, Cambridge, UK, 2001.

[12] E. Symeonakis, R. Bonifaçio, and N. Drake, "A comparison of rainfall estimation techniques for sub-Saharan Africa," International Journal of Applied Earth Observation and Geoinformation, vol. 11, no. 1, pp. 15-26, 2009.

[13] J. A. Holmes, E. R. Cook, and B. Yang, "Climate change over the past 2000 years in Western China," Quaternary International, vol. 194, no. 1-2, pp. 91-107, 2009.

[14] Y. H. Ding, G. Y. Ren, G. Y. Shi et al., "National assessment report of climate change (I): climate change in China and its future trend," Advances in Climate Change Research, vol. 2, no. 1, pp. 3-8, 2006.

[15] Y. X. Liu, X. Li, Q. Zhang, Y. F. Guo, G. Gao, and J. P. Wang, "Simulation of regional temperature and precipitation in the past 50 years and the next 30 years over China," Quaternary International, vol. 212, no. 1, pp. 57-63, 2010.

[16] C. J. Zhang, X. J. Gao, and H. Y. Zhao, "Influences of fall precipitation in Northwest China with global warming," Journal of Glaciology and Geocryology, vol. 25, no. 2, pp. 157-164, 2003.

[17] H. B. Mann, "Nonparametric tests against trend," Econometrica, vol. 13, pp. 245-259, 1945.

[18] M. G. Kendall, Rank Correlation Methods, Griffin, London, UK, 1975.

[19] R. M. Hirsch, J. R. Slack, and R. A. Smith, "Techniques of trend analysis for monthly water quality data," Water Resources Research, vol. 18, no. 1, pp. 107-121, 1982. 

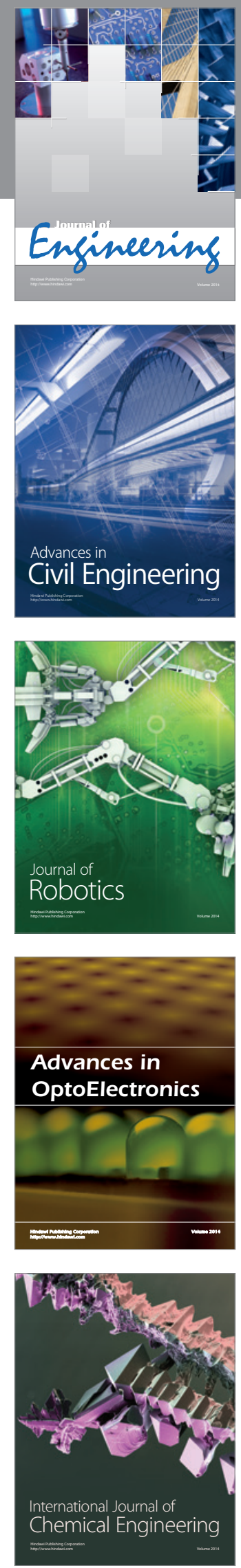

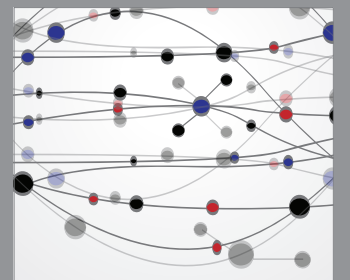

The Scientific World Journal
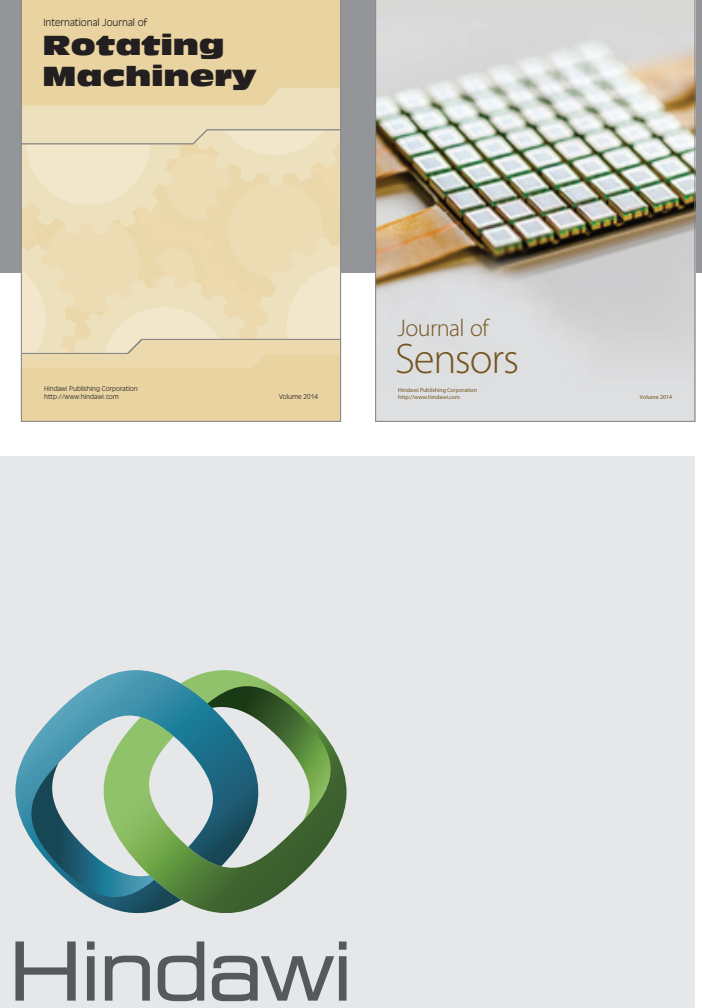

Submit your manuscripts at http://www.hindawi.com
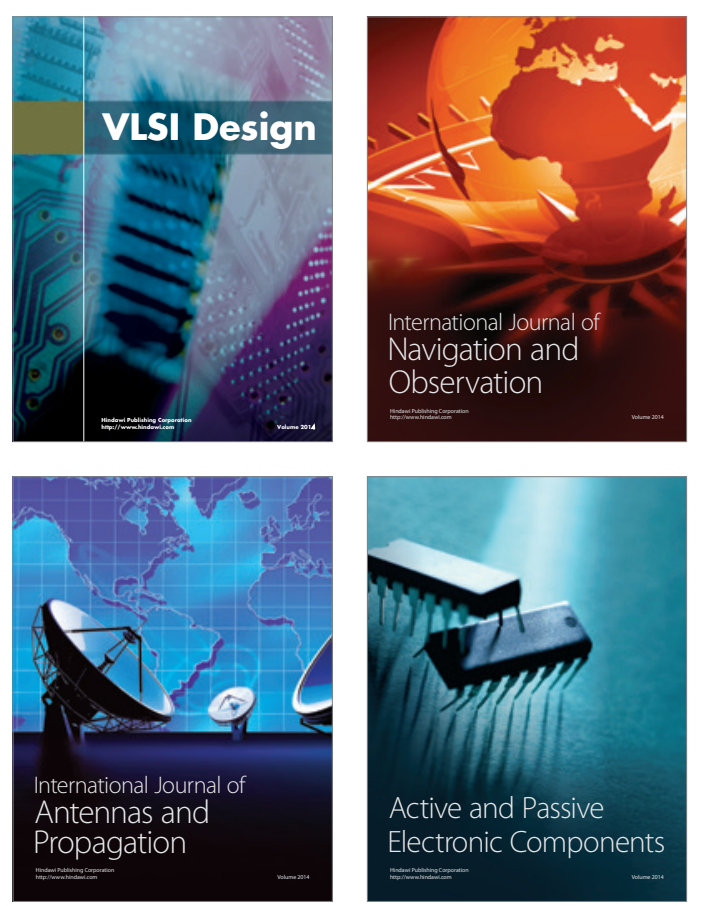
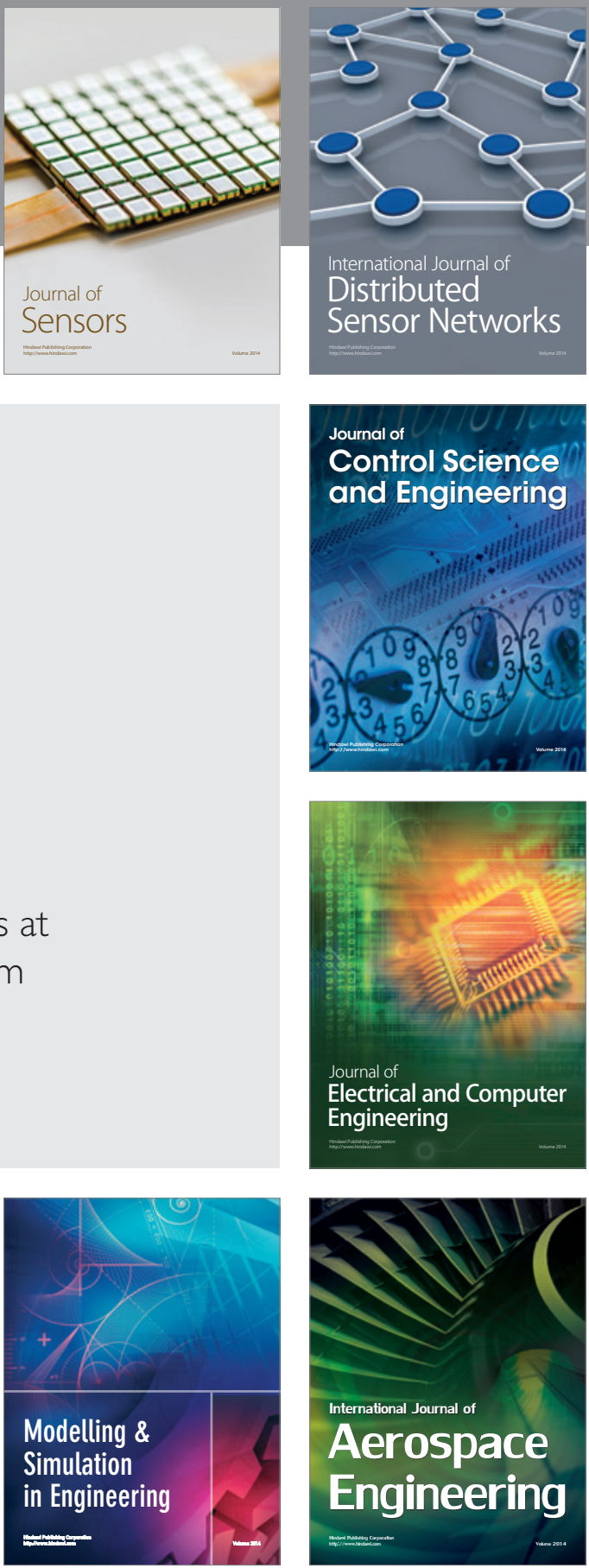

Journal of

Control Science

and Engineering
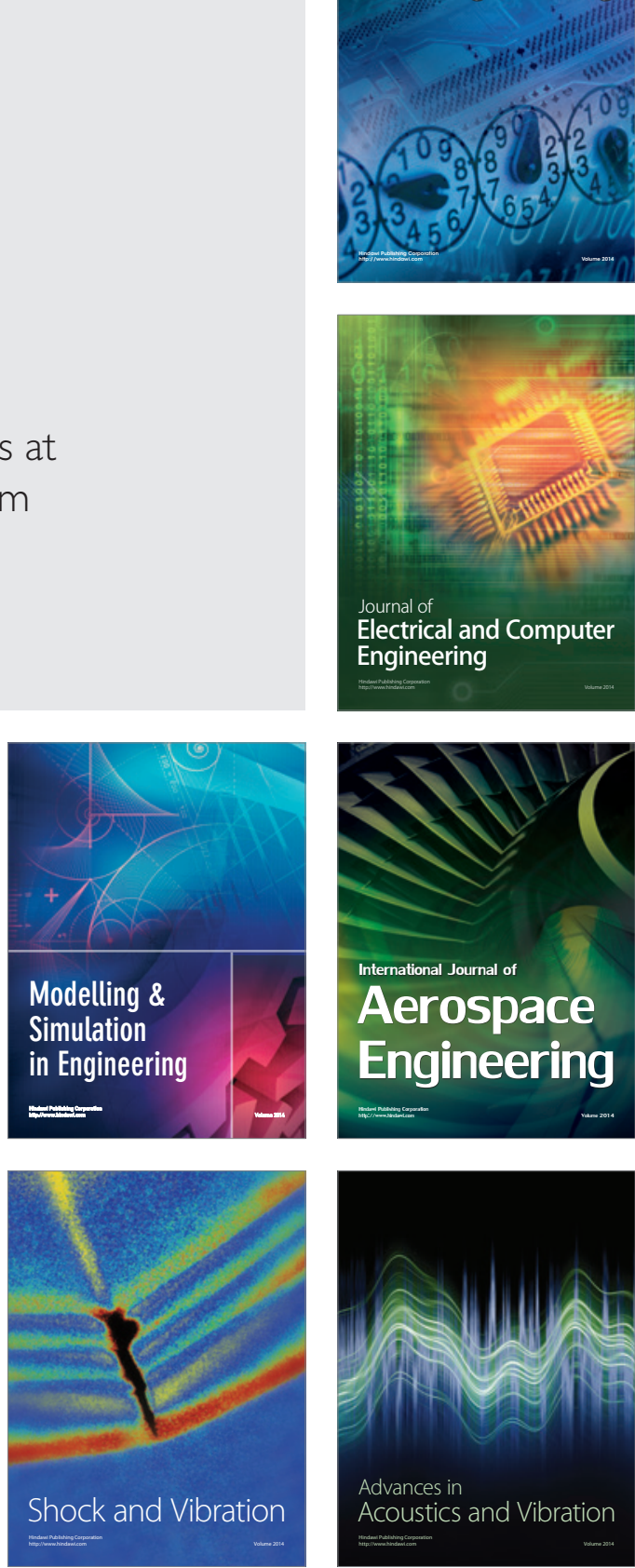